\title{
Trends in dental visiting avoidance due to cost in Australia, 1994 to 2010: an age-period-cohort analysis
}

Sergio Chrisopoulos", Liana Luzzi and David S Brennan

\begin{abstract}
Background: The cost of dental care may be a barrier to regular dental attendance with the proportion of the Australian population avoiding or delaying care due to cost increasing since 1994. This paper explores the extent to which age, period and cohort factors have contributed to the variation in avoiding or delaying visiting a dentist because of cost.

Methods: Data were obtained from four national dental telephone interview surveys of Australian residents aged five years and over conducted in 1994, 1999, 2004 and 2010 (response rates 48\% - 72\%). The trend in the percentage of persons avoiding or delaying visiting a dentist because of cost was analysed by means of a standard cohort table and more formal age-period-cohort analyses using a nested models framework.

Results: There was an overall increase in the proportion of people avoiding or delaying visiting a dentist indicating the presence of period effects. Financial barriers were also associated with age such that the likelihood of avoiding because of cost was highest for those in their mid-late twenties and lowest in both children and older adults. Cohort effects were also present although the pattern of effects differed between cohorts.

Conclusion: The findings of this study suggest that, in addition to the increase in costs associated with dental care, policies targeting specific age groups and income levels may be contributing to the inequality in access to dental care.
\end{abstract}

Keywords: Age, Period, Cohort, Financial barriers, Dental, Access

\section{Background}

In Australia, the cost of dental care falls largely on the individual. In 2009-10 individuals paid directly out-of-pocket $61.1 \%$ of all dental costs in Australia, compared to 24.5\% from state or federal government sources and $14 \%$ from private health insurance $[1,2]$. Dental care not only imposes a large cost on individuals, but dental fees have risen over time with the relative costs of dentistry increasing at a faster rate than other health expenditures [3]. As a result, the cost of dental care may become a barrier to people making regular dental visits and potentially adversely influencing the timeliness and comprehensiveness of care that is sought [4].

Issues of affordability and hardship in relation to dental care are salient for a substantial proportion of the

\footnotetext{
* Correspondence: sergio.chrisopoulos@adelaide.edu.au

Australian Research Centre for Population Oral Health, School of Dentistry, The University of Adelaide, 5005 Adelaide, South Australia, Australia
}

population. For example, the proportion of Australian adults who reported that they avoided or delayed dental care because of the cost increased from $27.1 \%$ in 1994 to $34.3 \%$ in 2008 [5]. What is not evident is whether this increase is due to age effects, period effects or cohort effects. Age effects are associated with physiological changes, accumulation of social experience, and/or role or status changes associated with growing up and aging. Period effects can result from shifts in social, cultural, or physical environments that affect the whole population simultaneously, e.g. changes in oral health policy affecting the whole population. Cohort effects are associated with changes across groups of individuals who experience an initial event such as birth in the same year or years, e.g. changes in oral health policies targeting specific age groups such as the elderly or children [6-8].

Identifying the influence of age, period and cohort effects aides to the interpretation of trends in health or

\section{Biomed Central}

(c) 2013 Chrisopoulos et al.; licensee BioMed Central Ltd. This is an Open Access article distributed under the terms of the Creative Commons Attribution License (http://creativecommons.org/licenses/by/2.0), which permits unrestricted use, distribution, and reproduction in any medium, provided the original work is properly cited. 
behaviour [9]. For example, financial barriers to dental care may be minimal in younger age groups because of access to school dental services, but increase with age as individuals are required to fund their own care. Similarly, changes in policy, such as the introduction of Life Time Health Cover in 2000 in Australia, which resulted in a 14 percentage point increase in the proportion of Australians with private health cover [10], may have resulted in dental care being more accessible for those with cover.

This study examines the extent to which age, period and cohort factors have contributed to variation in the proportion of dentate Australians aged 5 years and over who avoided or delayed visiting a dentist because of cost.

\section{Methods}

\section{Data source}

Data presented in this paper were sourced from the 1994, 1999, 2004 and 2010 National Dental Telephone Interview Surveys (NDTIS), conducted by the Dental Statistics and Research Unit at the University of Adelaide. These years were chosen to form approximately equal time intervals of five to six years. The NDTISs are national representative cross-sectional telephone interview surveys of Australian residents aged five years and over. Each survey consisted of a stratified random sample of Australian residents listed in the Electronic White Pages, and included questions on self-reported oral health and dental visiting characteristics. More detailed information on the NDTIS data collection methodology has been described elsewhere [5]. Response rates were $72 \%, 57 \%, 51 \%$ and $48 \%$, respectively, yielding a total of 41,467 completed interviews. Excluding edentulous persons and those aged less than 5 a total of 37,468 records were used in the present study ( $\mathrm{n}=6,928$ in 1994; $\mathrm{n}=6,901$ in 1999, $\mathrm{n}=14,140$ in 2004; and $\mathrm{n}=9,432$ in 2010). Ethics approval was obtained from the Australian Institute of Health and Welfare Ethics Committee for the 1994, 1999 and 2004 collections and the University of Adelaide Human Research Ethics Committee for the 2010 collection.

Data were weighted to represent the age and sex distribution of the Australian population at the time of each survey. Estimated resident population estimates used for the respective years were obtained from the Australian Bureau of Statistics.

In this study, financial barriers to dental care were assessed using the question "During the last 12 months, have you avoided or delayed visiting a dental professional because of the cost?" Respondents provided a simple "yes/no" response.

In addition, analyses were adjusted for sex and household income due to the reported relationship between these variables and avoidance in seeking dental care [5]. In the NDTIS, household income was collected as a categorical variable where respondents indicated the income range that most closely reflected that of the household. As these categories differed with each NDTIS, due to increasing household incomes over time, income ranges were grouped into roughly equal tertiles to allow any meaningful comparison.

\section{Analysis}

A standard cohort table was produced by creating 5-year age groups and corresponding 5-year birth cohorts. Age groups formed the rows of the table and time period formed the columns. In such a table, birth cohorts are represented in the diagonals of the table that run from the upper left to the lower right as illustrated for one cohort by the underlined figures in Table 1 . The percentage of dentate persons aged 5 years and over who avoided visiting a dental professional because of cost was calculated and are displayed. Age effects can be determined by examining differences within each cohort (i.e. intra cohort differences) by reading diagonally down and to the right; cohort effects by examining changes across cohorts (inter cohort changes) by reading down the columns; and period effects by comparing the same age group at one point in time with that at another point in time (i.e. by reading across the rows) $[9,11]$. This approach provides an initial description of trends however effects are confounded both age and cohort effects appear in column comparisons; cohort and period effects in row comparisons; and age and period effects in diagonal comparisons. For this reason, separation of age, period and cohort effects is difficult unless the observed effects are pronounced and consistent across all comparisons [11].

Clayton and Shifflers [12,13] developed a framework for age-period-cohort analyses based on nested regression models as a means to separate the effects of each component. This approach provides a technique which assesses the fit of different models rather than attempting to solve the intractable problem of identification inherent in age, period and cohort analysis. The identification problem comes because of the linear dependencies between the variables age, period, and cohort. As a result, only two of the three linear variables may be used in any particular model. The nested models approach therefore consists of fitting a series of models until adequate model fit is achieved.

The set of nested models that were fitted consisted of age, age-drift, age-period, age-cohort and age-periodcohort (APC) models, and adjusted for sex and household income tertile. The age model consisted of indicator variables for 18 age categories and forms the null hypothesis, that there is no temporal variation. The agedrift model consisted of the 18 indicators for age, and the four time periods entered as a continuous variable, to model trends not attributable to either period or cohort. Such variation is referred to as 'drift' [12-14]. The age-period model consisted of the 18 indicator variables for 
Table 1 Cohort table: Proportion of dentate persons who avoided or delayed visiting the dentist in the previous 12 months because of cost, by age group, birth cohort and data collection year (weighted\%, unweighted sample n)

\begin{tabular}{|c|c|c|c|c|c|c|c|c|c|c|c|c|c|c|c|c|}
\hline \multirow[b]{3}{*}{$\begin{array}{l}\text { Age group } \\
\text { (years) }\end{array}$} & \multicolumn{16}{|c|}{ Year of data collection } \\
\hline & \multicolumn{4}{|c|}{1994} & \multicolumn{4}{|c|}{1999} & \multicolumn{4}{|c|}{2004} & \multicolumn{4}{|c|}{2010} \\
\hline & $\begin{array}{c}\text { Birth } \\
\text { cohort }^{\mathrm{a}}\end{array}$ & $\underset{n}{\text { Sample }}$ & $\%$ & $\overline{S E}$ & $\begin{array}{c}\text { Birth } \\
\text { cohort }^{\mathrm{a}}\end{array}$ & 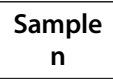 & $\%$ & SE & $\begin{array}{c}\text { Birth } \\
\text { cohort }^{\mathrm{a}}\end{array}$ & $\underset{n}{\text { Sample }}$ & $\%$ & $\overline{S E}$ & $\begin{array}{c}\text { Birth } \\
\text { cohort }^{\mathrm{a}}\end{array}$ & $\begin{array}{c}\text { Sample } \\
n\end{array}$ & $\%$ & $\overline{S E}$ \\
\hline $5-9$ & [4] & 563 & 12.5 & 1.88 & [3] & 446 & 9.3 & 1.81 & [2] & 578 & 6.9 & 1.24 & [1] & 946 & 12.4 & 1.55 \\
\hline $10-14$ & [5] & 510 & 15.0 & 2.20 & [4] & 461 & 11.1 & 2.22 & [3] & 710 & 9.9 & 1.40 & [2] & 1143 & 15.3 & 1.48 \\
\hline $15-19$ & [6] & 460 & 17.7 & 2.31 & {$[5]$} & 470 & 15.0 & 2.82 & [4] & 748 & 13.5 & 1.53 & [3] & 1189 & 19.6 & 1.88 \\
\hline $20-24$ & [7] & 567 & 31.3 & 2.49 & [6] & 372 & 27.6 & 3.17 & {$[5]$} & 610 & 32.2 & 2.26 & [4] & 416 & 32.3 & 3.09 \\
\hline $25-29$ & [8] & 647 & 33.7 & 2.46 & [7] & 517 & 36.8 & 3.10 & [6] & 739 & 46.3 & 2.38 & [5] & 320 & 40.2 & 3.88 \\
\hline $30-34$ & [9] & 721 & 35.5 & 2.27 & [8] & 586 & 32.5 & 2.81 & [7] & 1135 & 39.9 & 1.84 & [6] & 445 & 36.0 & 3.37 \\
\hline 35-39 & [10] & 596 & 32.4 & 2.62 & [9] & 591 & 29.0 & 2.62 & [8] & 1335 & 34.6 & 1.61 & [7] & 615 & 39.1 & 2.95 \\
\hline $40-44$ & [11] & 519 & 25.5 & 2.65 & [10] & 580 & 34.4 & 2.85 & [9] & 1375 & 38.0 & 1.60 & [8] & 716 & 32.6 & 2.38 \\
\hline $45-49$ & [12] & 472 & 23.4 & 2.50 & [11] & 533 & 29.3 & 2.96 & [10] & 1318 & 33.2 & 1.61 & [9] & 725 & 36.5 & 2.51 \\
\hline $50-54$ & [13] & 437 & 24.1 & 2.81 & [12] & 596 & 24.4 & 2.34 & [11] & 1216 & 29.9 & 1.63 & [10] & 760 & 29.6 & 2.20 \\
\hline $55-59$ & [14] & 358 & 23.0 & 2.94 & [13] & 439 & 26.1 & 3.21 & [12] & 1277 & 24.8 & 1.45 & [11] & 711 & 26.6 & 2.16 \\
\hline $60-64$ & [15] & 325 & 15.4 & 2.38 & [14] & 379 & 23.1 & 2.89 & [13] & 946 & 25.1 & 1.63 & [12] & 560 & 25.2 & 2.25 \\
\hline $65-69$ & [16] & 301 & 17.7 & 2.74 & [15] & 323 & 24.3 & 3.24 & [14] & 760 & 22.3 & 1.77 & [13] & 373 & 20.9 & 2.49 \\
\hline $70-74$ & [17] & 243 & 16.2 & 3.04 & [16] & 274 & 19.8 & 3.33 & [15] & 558 & 22.8 & 2.08 & [14] & 226 & 25.3 & 4.00 \\
\hline $75-79$ & [18] & 126 & 15.6 & 4.01 & [17] & 190 & 12.1 & 3.14 & [16] & 453 & 17.9 & 2.11 & [15] & 133 & 21.2 & 4.78 \\
\hline $80-84$ & [19] & 63 & 8.2 & 4.54 & [18] & 105 & 12.8 & 4.67 & [17] & 264 & 8.1 & 1.85 & [16] & 95 & 11.9 & 3.74 \\
\hline 85-89 & [20] & 14 & - & - & [19] & 30 & 8.8 & 5.47 & [18] & 100 & 11.4 & 3.59 & [17] & 48 & 14.7 & 7.19 \\
\hline $90-94$ & [21] & 6 & - & - & [20] & 7 & 12.3 & 11.91 & [19] & 17 & 6.0 & 5.91 & [18] & 10 & 4.2 & 4.41 \\
\hline Total & & 6,928 & 24.2 & 0.69 & & 6,901 & 24.5 & 0.77 & & 14,140 & 27.3 & 0.48 & & 9,432 & 28.2 & 0.73 \\
\hline
\end{tabular}

airth cohorts: \#1: born between 2000-2004; \#2: 1995-1999; \#3: 1990-1994; \#4: 1985-1989; \#5: 1980-1984; \#6: 1975-1979; \#7: 1970-1974; \#8: 1965-1969; \#9: 1960-1964; \#10: 1955-1959; \#11: 1950-1954; \#12: 1945-1949; \#13: 1940-1944; \#14: 1935-1939; \#15: 1930-1934; \#16: 1925-1929; \#17: 1920-1924; \#18: 1915-1919; \#19: 1910-1914; \#20: 1905-1909; \#21: 1900-1904.

age and the four time periods entered as indicator variables. The age-cohort model consisted of the 18 indicator variables for age and 21 indicator variables for birth cohorts. Finally, the age-period-cohort model consisted of the indicator variables for age, time period and birth cohort.

Due to the complex survey design of the surveys, the LOGISTIC procedure in SUDAAN [15] software was used to generate estimates and associated confidence intervals (i.e., to correctly estimate variance for complex surveys). Models were compared using difference in deviances of the nested models (likelihood ratio tests which approximately follows a Chi-square distribution) with the appropriate degrees of freedom $[9,12,13]$. Direct comparison of the age-period and age-cohort models is not possible using this approach [12]. The goodness-of-fit of the models was assessed using the Hosmer-Lemeshow test [16], with a P-value $<0.05$ indicating a lack of fit, and hence an inadequate model. A perfect model fit is indicated by a Hosmer-Lemeshow test statistic $=0$ and a P-value $=1$.

\section{Results}

Table 1 shows the proportion of dentate persons who reported that they avoided or delayed a visit to the dentist in the previous 12 months because of cost, along with the number of respondents to each survey by age and time of survey. With the exception of the older age groups, cells contain more than 50 participants. While estimates for these age groups have been included for completeness they should be treated with caution.

Cohorts can be traced by following the diagonals from left to right. For this cohort the proportion reporting that they avoided because of cost initially decreased from $12.5 \%$ in 1994 to $11.1 \%$ in 1999 and then increased to $32.3 \%$ in 2010 .

Figure 1 shows the proportion of people who reported that they avoided or delayed visiting a dentist because of cost by age group and year of data collection. The proportion avoiding care was lowest for children/adolescents and older adults, and highest for young adults. The general trend for children and adolescents was a decrease in dental visiting avoidance between 1994 and 2004 followed by an abrupt increase to 1994 levels. For adults, the proportion avoiding due to cost tended to increase over the four time periods but this was not consistent.

Figure 2 shows the age-specific prevalence of avoidance due to cost in successive cohorts. Each line represents a birth cohort passing through time and age. There was 


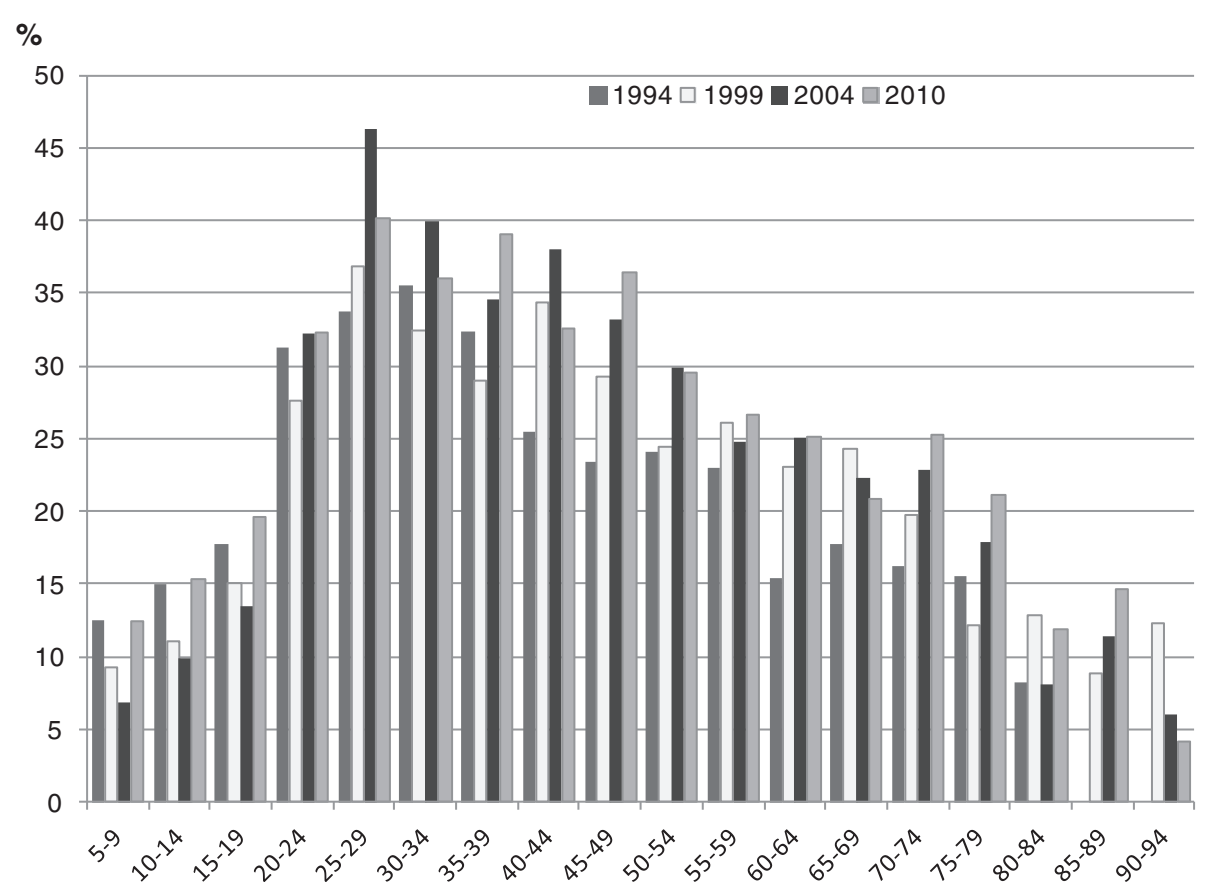

Figure 1 Proportion avoiding or delaying visiting a dentist in the previous year because of cost, by age and year of data collection.

a marked increase in avoidance due to cost for younger cohorts up to 25-34 years of age. For young to middleaged adult cohorts, the overall trend was a slight increase in the proportion avoiding care, while there was an overall decrease in avoidance for older adults.

\section{Model fit}

The Hosmer-Lemeshow goodness-of-fit test was used to assess how well each model fit the data (i.e. how well the model explained the variation in the proportion avoiding care because of cost). Controlling for income and sex, the Age-Drift model did not fit the data indicating that the variance in dental visiting avoidance could be attributed to period or cohort effects. The Age-Period and the Age-Period-Cohort models fit the data while the Age-Cohort model did not (Table 2). To assess whether one model had a better fit over another, the difference in the deviance statistic was used (Table 3). Both the Age-Period and Age-Cohort models had a better fit than the Age-Drift models. There is no formal test to determine whether the Age-Period was a better fitting model than the Age-Cohort model [12]. The AgePeriod-Cohort model provided the best fit for the data, indicating that period effects and birth cohort effects were influential on avoidance trends in seeing a dentist because of cost. As age, period and cohort effects are not independent, both the age-period and age-cohort models were examined in order to interpret the effects of age, period and birth cohort on avoidance in seeing a dentist because of cost.
The results of the Age-Period model indicate that people aged less than 25 and those 45 years and over were less likely to avoid or delay visiting a dentist because of cost than the reference category of 30-34 year-olds (with Odds ratios ranging from 0.10 for $80-84$ year olds to 0.79 for 20-24 year olds). The estimate for 90-94 year olds should be treated with caution due to the small number of respondents in this age group. In terms of period effects, respondents in 1999, 2004 and 2010 were more likely to avoid because of cost than those in 1994 (Table 4).

In the Age-Cohort model, people younger than 25, and those aged between 60 and 84 were less likely than 30-34 year olds to avoid because of cost (ranging from 0.15 for 5-9 year olds to 0.70 for the 20-24 year olds). For Birth cohort, those born prior to 1950 were less likely to avoid because of cost than those born 1965-1969 (ranging from 0.26 for those born in 1910-1914 to 0.72 for those born 1945-1949), and those born 1970-1984 were more likely to avoid attending because of cost (ranging from 1.26 for those born in 1970-1974 to 1.33 for those born in 1980-1984).

\section{Discussion}

This paper explores trends in financial barriers to dental care, conceptualised as avoidance or delay in visiting a dentist due to cost. Previous studies that have looked at trends in access associated with financial barriers to oral health, have mainly involved regression techniques and simple descriptive analyses [5,17]. This study employed an age-period-cohort analysis developed 


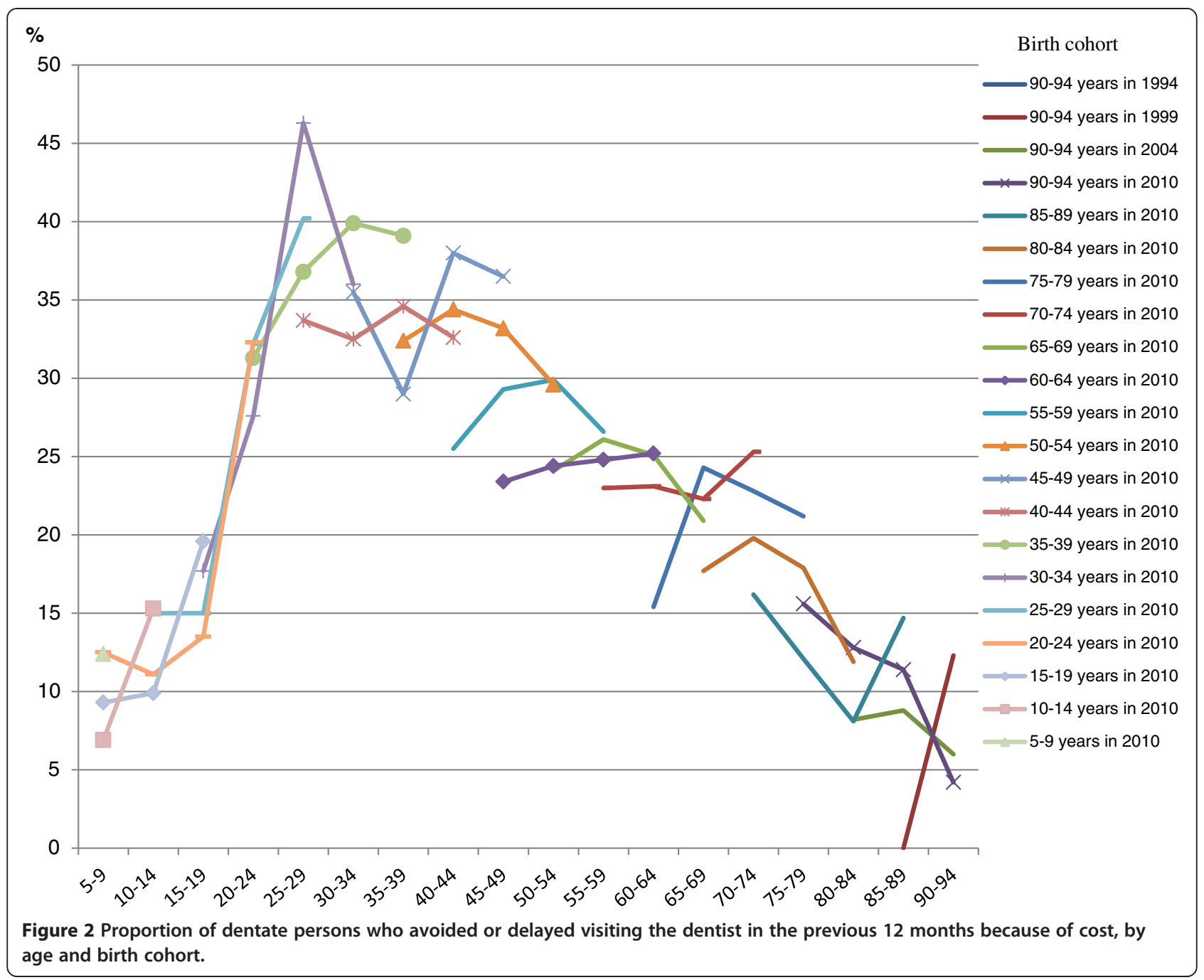

in the epidemiological context [12,13], applied to oral health services research.

Trends in avoidance or delaying dental visits because of cost The present study found clear effects associated with age structure that the proportion of the population avoiding or delaying a visit because of cost increased to a peak at around age 25-29 and then gradually declined. Controlling for age structure, there were also clear period effects that the proportion of persons avoiding or delaying care because of cost increased over time. However, the cohort effects indicate that the increase was not consistent across all birth cohorts. Compared to those who were born between 1965 and 1969, older cohorts were less likely, and those who were born between 1970 and 1984 were more likely to avoid or delay visiting because of cost.

Some of the variation in visiting patterns by age groups and by birth cohort may be influenced by, although not

Table 2 Logistic regression models goodness-of-fit test statistics

\begin{tabular}{|c|c|c|c|c|}
\hline \multirow[t]{2}{*}{ Model } & \multirow[t]{2}{*}{ Independent variables } & \multicolumn{3}{|c|}{ Hosmer-Lemeshow goodness-of-fit test } \\
\hline & & Chi-Square & DF & P-value \\
\hline Age & Age (categorical) & 12.91 & 8 & 0.12 \\
\hline Age + Drift & Age (categorical) + Period (continuous) & 25.89 & 8 & 0.00 \\
\hline Age + Period & Age (categorical) + Period (categorical) & 13.74 & 8 & 0.09 \\
\hline Age + Cohort & Age (categorical) + Cohort (categorical) & 23.41 & 8 & 0.00 \\
\hline Age + Period + Cohort & Age (categorical) + Period (categorical) + Cohort (categorical) & 10.99 & 8 & 0.20 \\
\hline
\end{tabular}


Table 3 Successive testing of models: analysis of deviance for nested models

\begin{tabular}{lccc}
\hline Comparison of models & Difference in deviance & DF & P-value \\
\hline Age-Drift vs. Age & 35.23 & 1 & $<.001$ \\
\hline Age-Period vs. Age-Drift & 44.23 & 2 & $<.001$ \\
\hline Age-Cohort vs. Age-Drift & 38.94 & 19 & $<.01$ \\
\hline Age-Period-Cohort vs. Age-Period & 34.06 & 19 & $<.05$ \\
\hline Age-Period-Cohort vs. Age-Cohort & 39.35 & 2 & $<.001$ \\
\hline
\end{tabular}

Table 4 Odds ratios (OR) with $95 \%$ Confidence Intervals (CI) from age-period and age-cohort models: Avoided or delayed visiting the dentist in $<12$ months because of cost

\begin{tabular}{|c|c|c|c|c|c|c|}
\hline \multirow[b]{2}{*}{ Parameter } & \multicolumn{3}{|c|}{ Age-period model } & \multicolumn{3}{|c|}{ Age-cohort model } \\
\hline & OR & $(95 \% \mathrm{Cl})$ & P-value & OR & $(95 \% \mathrm{Cl})$ & P-value \\
\hline \multicolumn{7}{|l|}{$\operatorname{Age}^{\mathrm{a}}$} \\
\hline $5-9$ & 0.17 & $(0.14,0.22)$ & 0.000 & 0.15 & $(0.10,0.22)$ & 0.000 \\
\hline $10-14$ & 0.22 & $(0.18,0.27)$ & 0.000 & 0.20 & $(0.14,0.27)$ & 0.000 \\
\hline 15-19 & 0.34 & $(0.28,0.42)$ & 0.000 & 0.30 & $(0.22,0.40)$ & 0.000 \\
\hline $20-24$ & 0.79 & $(0.66,0.95)$ & 0.014 & 0.70 & $(0.56,0.87)$ & 0.001 \\
\hline $25-29$ & 1.15 & $(0.96,1.36)$ & 0.130 & 1.08 & $(0.90,1.29)$ & 0.413 \\
\hline $30-34$ & ref. & - & - & ref. & - & - \\
\hline $35-39$ & 0.90 & $(0.76,1.06)$ & 0.198 & 0.96 & $(0.81,1.14)$ & 0.623 \\
\hline $40-44$ & 0.88 & $(0.75,1.04)$ & 0.129 & 1.06 & $(0.88,1.27)$ & 0.545 \\
\hline $45-49$ & 0.78 & $(0.66,0.91)$ & 0.002 & 1.00 & $(0.81,1.23)$ & 0.983 \\
\hline $50-54$ & 0.61 & $(0.52,0.72)$ & 0.000 & 0.87 & $(0.69,1.10)$ & 0.250 \\
\hline $55-59$ & 0.51 & $(0.43,0.60)$ & 0.000 & 0.82 & $(0.63,1.06)$ & 0.134 \\
\hline $60-64$ & 0.37 & $(0.30,0.44)$ & 0.000 & 0.63 & $(0.47,0.85)$ & 0.003 \\
\hline $65-69$ & 0.29 & $(0.24,0.36)$ & 0.000 & 0.54 & $(0.39,0.76)$ & 0.000 \\
\hline 70-74 & 0.29 & $(0.22,0.36)$ & 0.000 & 0.61 & $(0.41,0.91)$ & 0.016 \\
\hline 75-79 & 0.20 & $(0.15,0.26)$ & 0.000 & 0.49 & $(0.30,0.79)$ & 0.004 \\
\hline $80-84$ & 0.10 & $(0.06,0.15)$ & 0.000 & 0.29 & $(0.16,0.53)$ & 0.000 \\
\hline 85-89 & 0.13 & $(0.06,0.29)$ & 0.000 & 0.51 & $(0.19,1.35)$ & 0.174 \\
\hline 90-94 & 0.04 & $(0.01,0.16)$ & 0.000 & 0.22 & $(0.05,1.03)$ & 0.054 \\
\hline$\underline{95-99}$ & - & - & - & - & - & - \\
\hline \multicolumn{7}{|l|}{ Period $^{\mathrm{b}}$} \\
\hline 1994 & ref. & - & - & - & - & - \\
\hline 1999 & 1.17 & $(1.04,1.31)$ & 0.010 & - & - & - \\
\hline 2004 & 1.39 & $(1.26,1.54)$ & 0.000 & - & - & - \\
\hline 2010 & 1.22 & $(1.09,1.37)$ & 0.000 & - & - & - \\
\hline \multicolumn{7}{|l|}{ Cohort $^{c}$} \\
\hline 1900-1904 & - & - & - & - & - & - \\
\hline 1905-1909 & - & - & - & 0.06 & $(0.01,0.60)$ & 0.016 \\
\hline 1910-1914 & - & - & - & 0.26 & $(0.08,0.83)$ & 0.023 \\
\hline 1915-1919 & - & - & - & 0.39 & $(0.20,0.78)$ & 0.008 \\
\hline 1920-1924 & - & - & - & 0.37 & $(0.22,0.60)$ & 0.000 \\
\hline 1925-1929 & - & - & - & 0.52 & $(0.34,0.79)$ & 0.002 \\
\hline 1930-1934 & - & - & - & 0.60 & $(0.42,0.86)$ & 0.005 \\
\hline 1935-1939 & - & - & - & 0.68 & $(0.49,0.93)$ & 0.016 \\
\hline
\end{tabular}


Table 4 Odds ratios (OR) with $95 \%$ Confidence Intervals (CI) from age-period and age-cohort models: Avoided or delayed visiting the dentist in $<12$ months because of cost (Continued)

\begin{tabular}{|c|c|c|c|c|c|c|}
\hline$\underline{1940-1944}$ & - & - & - & 0.71 & $(0.53,0.94)$ & 0.019 \\
\hline 1945-1949 & - & - & - & 0.72 & $(0.56,0.92)$ & 0.008 \\
\hline 1950-1954 & - & - & - & 0.81 & $(0.65,1.01)$ & 0.056 \\
\hline 1955-1959 & - & - & - & 1.00 & $(0.83,1.21)$ & 0.995 \\
\hline 1960-1964 & - & - & - & 1.05 & $(0.90,1.23)$ & 0.522 \\
\hline 1965-1969 & - & - & - & ref. & - & - \\
\hline 1970-1974 & - & - & - & 1.26 & $(1.06,1.50)$ & 0.008 \\
\hline 1975-1979 & - & - & - & 1.30 & $(1.05,1.60)$ & 0.015 \\
\hline 1980-1984 & - & - & - & 1.33 & $(1.02,1.74)$ & 0.037 \\
\hline 1985-1989 & - & - & - & 1.32 & $(0.96,1.82)$ & 0.089 \\
\hline 1990-1994 & - & - & - & 1.30 & $(0.93,1.83)$ & 0.130 \\
\hline 1995-1999 & - & - & - & 1.22 & $(0.83,1.79)$ & 0.321 \\
\hline
\end{tabular}

${ }^{\mathrm{a}}$ Reference level = age group 30-34 years.

${ }^{\mathrm{b}}$ Reference level = year 1994.

${ }^{\mathrm{c}}$ Reference level = birth cohort 1965-69.

Note: Model has been adjusted for sex and household income tertile.

necessarily a result of, public oral health funding schemes in Australia, targeted at various age groups. For example, the lower rates of avoidance because of cost in younger children runs parallel with school dental services that provide free or subsidised dental care to children up to the age of 15 years in most jurisdictions in Australia. From 2008, subsidised dental care was extended to include teenagers of eligible families in the form of teen dental vouchers towards their dental care, although this was restricted to families who received Family Tax Benefit A [18,19]. From age 18, public funding for dental care is only provided to those with health care cards which may explain the sharp rise in affordability issues for these age groups.

The pattern of avoidance or delay due to cost for those aged 30 years and over indicates a mixture of both age effects and period effects. On the one hand, the rate of avoidance shows a gradual decline with increasing age (age effects). This coincides with people establishing themselves in the workforce and therefore potentially in a better financial position to afford dental care, either through higher incomes or through the provision of private health insurance. The lower rates of avoidance for those in their thirties also coincides with a series of initiatives by the Australian government to encourage people to take up private health insurance (which includes dental cover). These initiatives include the introduction of a $30 \%$ rebate for private health insurance in 1999 and the introduction of Life Time Health Cover the following year, which meant that if an individual did not have private cover by their $31^{\text {st }}$ birthday and then decided to obtain cover later in life then they would need to pay an additional $2 \%$ loading on their premium for every year over 30 that the individual was not insured $[10,20]$. This resulted in an increase in the proportion of the population with private health insurance of about 15 percentage points (from about 30\% to approximately $45 \%$ ) [10].

In addition to the increase in the proportion insured, the lower rates of avoidance due to cost in the older age groups may be associated with the Allied Health and Dental Care initiative introduced in 2004. This allowed patients with enhanced primary care plans (due to chronic diseases) to become eligible to access Medicare benefits for up to 3 visits totalling $\$ 220$ per year and increasing to $\$ 2000$ in 2007. This was extended to included residents of age care facilities managed by a general practitioner [18].

While there were clear age effects, period effects were also evident. There was an overall increase in avoidance because of cost for most age groups over the four time points, although this pattern differed by age group. Possible influencing factors for the increase may include the cost of dental care. For example, it has been reported that private dental fees increased by $50.8 \%$ between 1989-90 and 1998-99, compared to $22 \%$ for health prices over the same period [18]. More recently, the Australian Dental Association reported that between 2003 and 2008, the yearly increase in general practice fees ranged between $5.3 \%$ and $6.0 \%$, this was followed by a drop from $4.0 \%$ in 2009 to $1.3 \%$ in 2012 [21]. In comparison, the average annual growth in health inflation was $3.5 \%$ between $2000-01$ and 2005-06, followed by $2.3 \%$ between 2005-06 and 2010-11 [1].

\section{Strengths and limitations}

It has been argued that the use of the APC modelling strategy at a population level proposed by Clayton and Schifflers 
$[12,13]$ in the oral health context, ignores other factors associated with dental demand [7]. However, the purpose of this paper was not to create a predictive model, but rather to describe the trends in avoidance in seeking dental care and the role that age, birth cohort and period play. However, for the sake of completeness the model controlled for sex and household income. In addition, although not presented here, insurance status and perceived need for treatment were also included in the model, separately and combined however the models had poor fit indicating the reported APC model was a more appropriate one.

The major strength of this paper is the use of representative survey of the Australian resident population (NDTIS1994, NDTIS 1999, NDTIS 2004, NDTIS 2010). The high response rates, from $48 \%$ to $72 \%$, indicate that the results can be generalised to the population.

\section{Conclusion}

Overall, the use of Age-Period-Cohort analysis indicates that affordability of dental care is declining, although the pattern is not the same across age groups or birth cohorts. Policies targeting specific age groups appear to accentuate the differences in rates of avoiding or delaying dental care, especially for those in their twenties and thirties, contributing to inequalities in access to dental care.

\section{Competing interests}

The authors declare that they have no competing interests.

\section{Authors' contributions}

SC: SC provided the literature review, data analysis and interpretation of the underlying trends as well as drafting the manuscript. LL: LL assisted in the analysis and interpretation of the results and provided assistance in the drafting of this manuscript. DB: DB was responsible for the original conceptualisation of the research and the underlying methodological approach, as well as assisting in the drafting, editing and evaluation of the final manuscript. All authors read and approved the final manuscript.

\section{Acknowledgements}

The National Dental Telephone Interview Survey is supported by the Australian Government Department of Health and Ageing (AGDoHA), and the Australian Institute of Health and Welfare (AlHW). This manuscript was written with support from a Career Development Award (627037) and CRE (1031310) from the National Health and Medical Research Council (NHMRC). The contents are solely the responsibility of the authors, and do not reflect the views of the supporting bodies.

Received: 4 June 2013 Accepted: 30 September 2013

Published: 3 October 2013

\section{References}

1. Australian Institute of Health and Welfare: Health expenditure Australia 2010-11. Health and welfare expenditure series no. 47. Cat. no. HWE 56. Canberra: AlHW; 2012.

2. Chrisopoulos S, Beckwith K, Harford JE: Oral health and dental care in Australia: key facts and figures 2011. Cat. No. Den214. AlHW: Canberra; 2012.

3. Barnard PD: Australian Dental Practice Survey 2007, Report and tables. Sydney: Australian Dental Association; 2009.

4. Slade GD, Roberts-Thomson KF, Ellershaw A: Survey aims and methods. In Australia's dental generations: the National Survey of Adult Oral Health 2004-06. Edited by Slade GD, Spencer AJ, Roberts-Thomson KF. Canberra: Australian Institute of Health and Welfare (Dental Statistics and Research Series no. 34); 2007:11-36. Cat. no. DEN 165.
5. Harford JE, Ellershaw AC, Spencer AJ: Trends in access to dental care among Australian adults 1994-2008. Dental statistics and research series no. 55. Cat. No. DEN 204. AlHW: Canberra; 2011.

6. Glenn ND: Age, period and cohort effects. Encyclopedia Soc Meas 2005, 1:27-32.

7. Li KY, Wong MCM, Lam KF, Schwarz E: Age, period, and cohort analysis of regular dental care 1 behaviour and edentulism: A marginal approach. BMC Oral Health 2011, 11:9.

8. Yang Y, Land KC: Age-peiod-cohort analysis of repeated cross-section surveys. Fixed or random effects. Sociol Methods Res 2008, 36:297-326.

9. Bravo M: Age-period-cohort analysis of dentist use in Spain from 1987 to 1997. An analysis of the Spanish National Health Interview Surveys. Eur J Oral Sci 2001, 109:149-154.

10. Private Health Insurance Administration Council, PHIAC: Statistical Trends in Membership and Benefits Data Tables December 2012. http://phiac.gov.au/ annual_survey/annual-coverage-survey-data-tables-december-2011/.

11. Wolinsky FD, Arnold CL: A birth cohort analysis of dental contact among elderly Americans. Am J Public Health 1989, 79:47-51.

12. Clayton $D$, Schifflers E: Models for temporal variation in cancer rates. I: Age-period and age-cohort models. Stat Med 1987, 6:449-467.

13. Clayton D, Schifflers E: Models for temporal variation in cancer rates II: Age-period-cohort models. Stat Med 1987, 6:469-481.

14. Brennan DS, Ryan P, Spencer AJ, Szuster FSP: Dental service rates: age, period, and cohort effects. Community Dental health 2000, 17:70-78.

15. Research Triangle Institute, RTI: Sudaan Language Manual, Volume 11. 1 and 2nd edition. NC: RTI International; 2012.

16. Hosmer DW, Lemeshow S: Applied Logistic Regression. New Yoirk: John Wiley \& Sons; 1989.

17. Ramjaj C, Sadeghi L, Lawrence HP, Dempster L, Quiñonez C: Is accessing dental care becoming more difficult? Evidence from Canada's middleincome population. PLOS ONE 2013, 8(2):e57377.

18. Biggs A: Overview of Commonwealth involvement in funding dental care. Research paper. Canberra: Department of Parliamentary Services, Parliament of Australia; 2008.

19. Spencer AJ, Harford JE: Inequality in Oral Health in Australia. Australian Review of Public Affairs; 2007. http://www.australianreview.net/digest/2007/ election/spencer harford.html.

20. Harford JE, Spencer AJ: Government subsidies for dental care in Australia. Aust NZ J Public Health 2004, 28:363-368.

21. Tran D, Boyd-Boland R: Australian Dental Fees Survey 2012. Sydney: Australian Dental Association; 2012.

\section{doi:10.1186/1472-6963-13-381}

Cite this article as: Chrisopoulos et al:: Trends in dental visiting avoidance due to cost in Australia, 1994 to 2010: an age-period-cohort analysis. BMC Health Services Research 2013 13:381.

\section{Submit your next manuscript to BioMed Central and take full advantage of:}

- Convenient online submission

- Thorough peer review

- No space constraints or color figure charges

- Immediate publication on acceptance

- Inclusion in PubMed, CAS, Scopus and Google Scholar

- Research which is freely available for redistribution 